\title{
Análise comparativa dos efeitos da base socioeconômica, dos tipos de crime e das condições de prisão na reincidência criminal ${ }^{*}$
}

\section{Introdução}

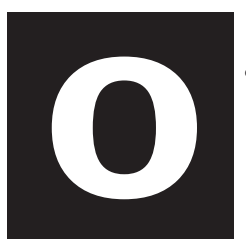

problema da reincidência ou "recidivismo" criminal não é apenas um agravante da questão da criminalidade primária, mas constitui a espinha dorsal das chamadas carreiras criminais, ao redor das quais o fenômeno da criminalidade adquire uma dimensão estrutural dentro da sociedade. A reincidência criminal representa o fracasso do esforço social pela re-socialização dos infratores e a consolidação da sua exclusão. A compreensão deste fenômeno e da sua antítese - os programas e possibilidades de re-socialização - são uma necessidade apremiante. Ora, a pesquisa social em criminologia no Brasil reconhecidamente caminha muito lentamente, e a questão da reincidência participa com destaque desta grave lacuna.

O objetivo central do presente artigo é identificar, quantificar e comparar os efeitos isolados das seguintes três dimensões causais hipotéticas da reincidência criminal: "condições prisionais" (relativas a várias características institucionais das prisões), "condições socioeconômicas" (características econômicas, educacionais, religiosas e raciais), e tipo de crime (em

\footnotetext{
* A tradução do original em Inglês é de autoria de Roberto Cataldo Costa.

**Professor Titular de Sociologia da Universidade Federal do Rio Grande do Sul, Ph.D em Sociologia pela Universidade de Wisconsin.
} 
termos de uma tipologia resumida), pesquisados diretamente nos registros oficiais do sistema prisional da Secretaria de Justiça do Rio Grande do Sul (Brasil). A intenção básica do trabalho é proporcionar bases empíricas para políticas prisionais e de justiça criminal, a partir da avaliação metodológica dos determinantes causais da reincidência em questão. A análise pretende, pois, determinar em que medida as condições de prisão são responsáveis pela reincidência criminal, controlando, via análise multivariada, pelo status socioeconômico e os tipos de crime. Isto ajuda a estimar, com rigor metodológico, até que ponto a manipulação das condições de prisão pode diminuir a reincidência, levando em consideração os efeitos de outras duas dimensões a partir da recente experiência prisional do Estado.

Com base nos resultados da pesquisa elaboramos, a título de conclusão, algumas reflexões sobre as possibilidades da re-socialização no contexto Brasileiro e da América Latina, em contraposição à chamada new penology (nova filosofia prisional), que é a tendência mais recente do enfoque sobre a questão dos objetivos e métodos prisionais nos Estados Unidos, e que tende a estender-se no mundo em geral.

\section{Revisão da literatura}

A literatura sobre a reincidência criminal tem abordado parcialmente esta questão. Salientamos em primeiro lugar o trabalho de Lattimore et al. (1995), que estudaram a predição de segunda detenção (rearrest) por atos violentos, para um grupo de infratores jovens, em termos do seu "histórico criminal", "comportamento institucional" e características pessoais. Estes autores concluíram que uma predição prática neste sentido pode ser feita, desde que os três fatores sejam levados em consideração. Ora, mesmo que o nosso recorte aqui seja um pouco diferente, a semelhança entre os dois desenhos é notória, e respalda a viabilidade da idéia geral do presente trabalho.

As pesquisas existentes sobre a reincidência criminal também fornecem algumas idéias sobre os seus determinantes ou fatores institucionais 
condicionantes, além do impacto esperado a partir de programas planejados de re-socialização. Sobre estas pesquisas indicamos em primeiro lugar a crença - virtualmente universal entre os investigadores - na total falta de efetividade da prisão, em si mesma, como estimuladora de comportamento dentro da lei, nos infratores. Mais ainda, esta crença freqüentemente é radicalizada, em termos de uma suposta tendência das prisões de induzir em lugar de reduzir - a reincidência criminal. Tanto a bem conhecida "teoria da rotulação" (labeling-theory) como algumas pesquisas empíricas, fornecem apoio a esta hipótese (Sherman et al., 1992; Salem, 1995; Weisburd et al., 1995). Anteriormente, inclusive, Sherman e Berk (1984) haviam levantado argumentos com relação à reincidência, baseados na existência de reações diferentes por parte dos agentes policiais com relação a suspeitos, e correspondentes diferenças de tratamento no subseqüente trabalho de acompanhamento.

A questão da reincidência nesta ótica acaba sendo interpretada como um problema de discriminação tanto quanto um problema derivado da experiência prisional em si. Ora, quando falamos em "condições de prisão", nos referimos aqui especificamente à qualidade das acomodações nas prisões (especialmente super-lotação), qualificação do funcionalismo, assim como aos programas educacionais e oportunidades de trabalho e várias formas de assistência social ao apenado (aconselhamento e trabalho de serviço social). Desse ponto de vista, tanto as oportunidades de trabalho para os apenados como os programas educativos e de treinamento ocupacional devem naturalmente, por hipótese, reduzir a reincidência. Assim mesmo, estes programas de educação e trabalho devem, por hipótese, ajudar o apenado a se preparar para a procura de emprego quando liberado (Desroches, 1984). Pode ser aqui lembrado que o ócio prisional é freqüentemente visto como um fator chave estimulador de recidivismo (Eckered, 1988).

Ora, independentemente dos registros acadêmicos, amplos segmentos da comunidade política permanecem aferrados às teorias tradicionais do impacto do encarceramento, no sentido de que a simples punição por pri- 
vação da liberdade deve produzir um efeito de contenção (deterrance) no comportamento criminal.

Como resultado desta visão tradicional tem surgido no passado recente as conhecidas políticas repressivas amplas (encarceramento, tolerância zero, etc.), especialmente nos Estados Unidos. As recentes quedas notórias da criminalidade nesse pais são imputadas a tais políticas repressivas. Porém, o contraponto empírico a estas interpretações surge do paralelo estabelecido entre as quedas nas taxas de criminalidade em questão e o desempenho altamente favorável da economia desse país nas décadas de 80 e 90, somado ao envelhecimento abrupto da população no mesmo período, exacerbado pelo chamado baby boom. Junto com estes contraargumentos, aparece também no debate, ainda com relação à experiência Norte-americana, a falta de uma associação entre gastos em privação da liberdade e redução da criminalidade, quando se consideram os estados da união como unidade de análise. O debate, pois, entre as duas teorias sobre o impacto da reincidência (rotulação vs. "Contenção repressiva") não está ainda esclarecido, mais ainda tendo em vista o componente explicativo adicional, ainda também não esclarecido, da teoria da escolha racional no crime (Shover e Honaker, 1992).

Com relação à base socioeconômica como condicionante da reincidência, nos Estados Unidos tem se observado fortes tendências discriminatórias contra os negros e outras minorias na primeira detenção. Porém, nas probabilidades de posteriores detenções, o fator raça não apresenta resultados consistentes: Blumstein e Graddy (1981) oferecem resultados de pesquisa sem diferenças significativas, enquanto Martinez (1992) e McCord (1983) encontram que há um impacto significativo deste fator. Na Austrália, fortes diferenças no mesmo sentido entre aborígines e outros são bem conhecidas (Broadhurst e Loh, 1995). Por tanto, a medida em que o fator raça seja um fator determinante do recidivismo, e qual seja a posição hierárquica deste fator frente a outros, é uma questão empírica, histórica e regionalmente específica. 
Também notório quanto a base socioeconômica é naturalmente a própria condição econômica. No caso da Austrália, por exemplo, todos os aborígines que sofreram segunda detenção estavam desempregados, e não tinham qualquer base financeira no momento da liberação (Alexander, 1987). Porém, um estudo importante sobre a relação entre base econômica e crime na antiga lugoslávia (Zevick, 1990) conclui pela impossibilidade de generalização sobre esta relação, porquanto ela muda de direção e intensidade em formas drásticas, dentro de um padrão ainda não explicado. Então, assim como é, reconhecidamente, um erro atribuir primazia causal à pobreza como fator gerador de criminalidade, é também um erro atribuir a priori tal primazia no caso da reincidência.

A importância do fator gênero, por seu lado, junto com as variáveis demográficas clássicas como condicionantes da reincidência, pode ser apreciado por exemplo no trabalho de Greensberg (1991), dentro da tendência geral de criminalidade preponderante dos homens. Ora, quanto ao fator idade, de uma lado mostra-se que, quanto menor a idade do primeiro delito, maiores as probabilidades de reincidência (Martinez, 1992; Nagin, 1992). Porém, Block e Van-der-Werf (1987) encontram no seu estudo que a idade na primeira ofensa não tem conseqüências na reincidência.

Para efeitos de elucidar a questão da base econômica, dois fatores do recidivismo poderiam ser invocados: impacto de rotulação do processo policial-judicial e insuficiência financeira. Estes dois fatores, agindo em interação com a idade, podem explicar os resultados aparentemente inconsistentes, assim: de um lado, para os infratores mais jovens, o impacto maior do processo policial e judicial e da experiência prisional determina efeitos "positivos" (de aumento) na reincidência, dentro da línea teórica da rotulação. Ora, em termos do fator "insuficiência econômica", o momento mais delicado ou vulnerável não é na adolescência mas mais tarde, quando as responsabilidades econômicas e financeiras e a auto-imagem são muito mais importantes. Num entorno econômico de rápida mudança, isto pode ser crucial. 
O tipo de crime tem demonstrado ser o principal preditor de reincidência criminal. Lenke et al. (1982) argumentam que a informação sobre o tipo de antecedentes criminais é o fator singular mais importante na predição do recidivismo. O segundo delito tende a acontecer dentro do mesmo tipo de crime cometido na primeira instância delictiva, de acordo com Holland (1983), Alexander (1993) e Hanson, (1995). A possível exceção vem do trabalho de Grunfeld (1986) relativo às ofensas sexuais, que acontecem tanto antes quanto depois de outras ofensas.

Dentro do quadro investigativo geral sobre a reincidência apresentado, a presente pesquisa representa uma primeira tentativa de avaliar quantitativamente a questão do recidivismo em função dos fatores mencionados inicialmente, e nisto radica o seu principal mérito. Ora, o seu caráter é eminentemente exploratório, em função da base de dados disponível. Isto significa que os resultados das pesquisas referenciadas na revisão da literatura não serão diretamente testados no contexto do extremo sul do Brasil. Nosso objetivo específico é apenas selecionar uma bateria de indicadores das dimensões causais mencionadas e, de forma exploratória, quantificar e interpretar a associação multivariada destes indicadores com a reincidência em questão.

O valor destas associações e da sua significância estatística radica, pois, em determinar sim ou não, e em que medida, os programas de re-socialização estão tendo algum resultado palpável, e quais os grupos e contextos onde a reincidência tem maiores e menores probabilidades de acontecer.

\section{Dados e métodos}

A unidade de análise é o presídio. A limitação óbvia dessa unidade é o fato de que os apenados transitam por mais de uma casa prisional. Porém, na maioria dos casos, um presídio se destaca amplamente sobre os outros, e o impacto principal pode ser imputado a esse presídio onde o detento passou a maior parte do seu tempo como apenado. 
Utilizamos dois conjuntos distintos de dados originais, sendo que um deles é composto pelos formulários de dados prisionais elaborados e coletados pela SUSEPE1 . Os formulários de coleta de dados são preenchidos trimestralmente por funcionários dos presídios, sem que haja verificação posterior. Assim sendo, se podem esperar imprecisões, mas não existem bases para questionarmos a confiabilidade de tais dados como aproximações dos valores verdadeiros. Cinqüenta por cento da informação relativa ao período de 1987 a 1995 foi processada de forma eletrônica, cobrindo um a cada dois trimestres. Nossa análise trabalha com o conjunto deste meio-universo de dados. O segundo conjunto engloba o universo total das informações contidas no Cadastro de Informações sobre o Apenado (CIA), organizado na forma de dados eletrônicos pela PROCERGS, a partir dos registros oficiais do estado sobre os presídios. O mesmo período de 1987 a 1995, no caso de dados da SUSEPE, também foi utilizado com relação aos dados do CIA sobre apenados, da mesma forma que a estrutura trimestral anterior foi utilizada para este segundo conjunto de dados, agregando-se a informação de forma trimestral e por presídio.

A questão central aqui, a saber, a reincidência, é abordada de forma dicotômica, ou seja: compara-se uma entrada no sistema prisional do estado por parte dos apenados com mais de uma entrada ${ }^{2}$, considerando-se que, do ponto de vista teórico, a análise das diferenças causais entre uma ou mais entradas é um passo analítico anterior (mais simples) do que aquele relacionado à variação na escala de proporção mais ampla, formada pelo número variável de entradas apresentadas pelos reincidentes. Dessa forma, o tratamento dicotômico da reincidência nesse caso significa que o que está sendo analisado é o impacto das condições prisionais no desencadeamento ou não de carreiras criminais (sejam elas curtas ou longas), independentemente dos perfis socioeconômicos e criminológicos dos

1 A partir dessas informações, a instituição publica relatórios trimestrais com dados agregados sobre as características dos presídios.

2 Esta noção de "reincidência" difere do conceito jurídico de "recidivismo", o qual leva em conta o fato do apenado ter passado por todos os devidos procedimentos da justiça criminal, bem como o tempo transcorrido de uma entrada a outra. 
apenados e dos presídios. A reincidência foi calculada como sendo a quantidade de apenados que chegam a reincidir durante os dois primeiros anos após sua libertação, em relação ao total dos que deixam um determinado presídio. Por essa razão, assim como para todas as outras variáveis, foram construídas seqüências temporais na forma de unidades trimestrais. A partir daí, calculam-se as médias gerais para os períodos trimestrais. Para a análise multivariada, foram utilizadas as médias gerais dos presídios para o período de 1987 a 1997 como variáveis para análise ${ }^{3}$. Assim, através da técnica de regressão step-wise, foi possível identificar os indicadores de variáveis mais importantes (biográficos e institucionais), associados à reincidência. O status jurídico foi analisado calculando-se, para cada presídio, a proporção de apenados associada a cada tipo de crime.

\section{Reincidência e tendências gerais da criminalidade}

Apesar da falta de pesquisas sistemáticas sobre reincidência criminal no Brasil, algumas iniciativas isoladas oferecem um panorama geral do fenômeno, além de variações concomitantes com o passar do tempo, que são de interesse para a análise causal. O censo penitenciário nacional de 1994 demonstra que 34,4\% dos apenados eram reincidentes, ao passo que, no RS, essa porcentagem diminui para $29,9 \%$, e para os três estados da região sul, juntos, chega a $25,76 \%$. Os dados criminais oficiais analisados pelo convênio UFRGS-Secretaria da Justiça do RS (Dos Santos, 1997) demonstram que, no período entre 1986 e 1996, a proporção média de reincidentes era de $26,84 \%$, caracterizando um crescimento mensurável na década. Essa tendência é confirmada e inclusive ampliada pelos dados sobre reincidência para "recolhidos" (excluindo os casos de liberdade condicional) referentes aos anos de 1986 e 1995, onde a reincidência passou de

\footnotetext{
3 Variações importantes nos índices de reincidência já foram demonstradas na taxa básica e nos pontos de corte (Smith, 1996). Isso, contudo, afeta basicamente a comparabilidade, e não a validade historicamente específica da análise multivariada, que é a principal preocupação neste caso.
} 
$39 \%$ a 45\% nesse período. A seguir, descrevemos algumas mudanças globais no cenário prisional do estado, a partir de nossa visão tridimensional da causalidade com relação à reincidência. Porém, tais variações concomitantes, simples e gerais, estão geralmente abertas à supressão e mesmo à reversão dos seus efeitos através da intervenção de outras variáveis, e só podem ser consideradas como aproximações iniciais para auxiliar na interpretação da análise multivariada.

\section{Mudanças nas condições prisionais}

As principais mudanças recentes nas condições prisionais tem sido apresentadas em vários relatórios do Convênio UFRGS-Secretaria da Justiça do RS (Dos Santos, 1997) e são resumidas a seguir:

a) Um aumento sistemático no déficit da capacidade prisional relativa desde aproximadamente 1987. Até mais ou menos aquele ano, havia uma relação de certa forma equilibrada entre a população carcerária geral e a capacidade total dos presídios (próxima a 6.000); ainda assim, em 1994, a população carcerária subiu para mais de 11.000 , ao passo que a capacidade dos presídios aumentou em menos de 50\%.

b) Uma tentativa de compensar essa tendência ao déficit de capacidade pode ser identificada na quantidade crescente de pessoal de segurança nos presídios, que passou de cerca de 700 para algo em torno de 1.200, entre 1989 e 1997. O número geral de outros tipos de funcionários técnicos e administrativos permaneceu essencialmente o mesmo.

c) A qualificação dos funcionários dos presídios (de todos os tipos) melhorou significativamente no período de 1989 a 1997: o número de funcionários (de todos os tipos) que tinha apenas educação primária diminuiu de cerca de 1.450 para cerca de 250, enquanto o pessoal com educação secundária passou de em torno de 500 para mais de 1.000, e os que tinham educação superior foram de 350 para cerca de 600. 
d) A proporção de estabelecimentos prisionais que oferecem algum tipo de trabalho (dentro e/ou fora dos presídios) diminuiu de cerca de 97\% em 1991 para 89\% em 1997. Condizente com essa tendência de queda, a proporção de apenados trabalhando em qualquer função diminuiu de 57\% em 1987 para 40\% em 1997.

e) A proporção de presídios que ofereciam cursos de educação geral e/ou cursos técnicos subiu de 29\% em 1989 para 46\% em 1997.

f) A porcentagem de presídios que contava com algum tipo de aconselhamento e que dispunha de qualquer grupo de assistência aos apenados diminuiu de 79,77\% em 1989 para 27,47\% em 1997.

A partir dessas recentes transformações observadas, podemos inferir inicialmente que esses aumentos no déficit de espaço físico, por um lado, e diminuições das oportunidades de trabalho e assistência social, por outro, podem ter contribuído para o crescimento observado na reincidência. Além disso, os aumentos em pessoal de segurança, qualificação geral dos funcionários e oportunidades para treinamento e educação oferecidas aos apenados não conseguiram diminuir a reincidência. Porém, a análise multivariada apresentada posteriormente revelara que, apesar da mudança líquida negativa (mais reincidência), a contribuição isolada de alguns fatores é positiva. Antes de apresentar tal análise, retomamos a exposição das tendências isoladas.

\section{Mudanças no perfil criminal}

A Tabela 1 apresenta algumas mudanças no perfil criminológico dos presídios no período de 1989 a 1997. Estes perfis e suas transformações ao longo do tempo devem ser levados em consideração, não apenas por causa da hipótese amplamente aceita de que determinados tipos de crimes têm mais probabilidades de resultar em delitos posteriores do que outros, mas também porque a distribuição de tipos de crimes nos presídios não é aleatória, obedecendo a questões de segurança e outras políticas de alocação prisional. 
Em primeiro lugar, deve-se observar a diminuição no roubo, bastante surpreendente quando comparada com o aumento no volume total de crimes, o qual mais do que dobrou (estimado a partir do crescimento de 108\% na população carcerária). Esse resultado pode ser conseqüência da provável prioridade dada aos crimes mais sérios por parte da polícia e dos promotores face ao rápido aumento na criminalidade. Esta interpretação parte da idéia de que o volume total de crimes aumentou significativamente mais do que 108\% (já que se supõe uma subestimação nos registros de roubo). Outra mudança importante no perfil criminológico é sua diversificação e o surgimento de novas formas - como o seqüestro -, deduzidas a partir do próprio aumento significativo na categoria de "outros crimes". Nesse caso, mais uma vez, nada se pode inferir sobre seus efeitos específicos sobre a reincidência. Considerando-se os 108\% de aumento total da criminalidade no período de 1986 a 1997, apenas os crimes sexuais, o tráfico e a posse de drogas podem ser considerados como fatores contribuintes potenciais para o aumento da reincidência observados diretamente, devido ao seu crescimento desproporcional (145\% e 204\%, respectivamente). Todavia, como sua participação relativa no volume geral de crimes é bastante baixa (apenas 8,1\% dos crimes em 1986), sua participação na geração de reincidência deve ser igualmente baixa.

Pode-se observar outra transformação considerável no perfil criminal dos presídios: a porcentagem de apenados libertados por meio de habeascorpus, fim de sentença, falta de reconhecimento ou flagrante, indulto, fim de prisão preventiva e comutação de sentenças prisionais, que diminuiu de 26,2\% em 1989 para 9,1\% em 1997. Embora não seja possível afirmar uma relação direta entre essa mudança e a reincidência, pela teoria da contenção poderia se esperar um efeito benéfico (contra a reincidência). O escopo da nossa pesquisa, porém, não permite avançar neste ponto. 
Tabela 1. Freqüências dos Tipos de Crime por Ano, Hierarquia, e Aumentos no Período de 1986 a 1997

\begin{tabular}{c|c|c|c|c|c|c}
\hline Tipo de Crime & $\begin{array}{c}\mathbf{1 9 8 6} \\
\text { (abs.) }\end{array}$ & $\begin{array}{c}\mathbf{1 9 8 6} \\
\text { (\%) }\end{array}$ & $\mathbf{1 9 9 7}$ & $\begin{array}{c}\mathbf{1 9 9 7} \\
\text { Hierarquia }\end{array}$ & Resíduo & $\begin{array}{c}\text { Aumento } \\
\% \text { no } \\
\text { Período }\end{array}$ \\
\hline Roubos & 1,503 & 19,2 & 12.1 & 3 & -108 & -7 \\
\hline Homicídios & 941 & 17,2 & 15.3 & 2 & 831 & 88 \\
\hline Furtos/ Roubos & 921 & 16,8 & 15.5 & 1 & 870 & 94 \\
\hline Crimes Sexuais & 236 & 4,3 & 5.0 & 5 & 344 & 145 \\
\hline Lesões Corporais & 234 & 4,3 & 2.3 & 6 & 31 & 13 \\
\hline Tráfico de Drogas & 206 & 3,8 & 5.4 & 4 & 421 & 204 \\
\hline Estelionato & 68 & 1,2 & 1.1 & 7 & 35 & 51 \\
\hline Posse de Drogas & 39 & 0,7 & 4.0 & 8 & 425 & 1,089 \\
\hline Outros & 1,777 & 32,5 & 41.9 & - & 3,055 & 171 \\
\hline Dados não constantes & 43 & 0,7 & 0.6 & & 37 & 86 \\
\hline Total de Apenados & 5,518 & 100 & 11,5 & & 6,003 & 108 \\
\hline & & & 21 & & & \\
\hline
\end{tabular}

Fonte: Relatório de Pesquisa realizado pelo Convênio UFRGS-SJS (Dos Santos et al.:1997).

\section{Mudanças no status socioeconômico}

Com relação a este aspecto, primeiramente fazemos uma distinção entre as mudanças que podem ser, em última análise, associadas ao crime através das transformações nas condições econômicas e aquelas associadas ao crime através das transformações nas relações e condições sociais. Aqui, devemos alertar para os riscos de uma interpretação economicista da criminalidade e da reincidência criminal: mesmo que os fatores gerados economicamente possam ser mais facilmente identificados e operacionalizados, como parece ser o caso do que se segue, isso não significa que as condições econômicas sejam, na verdade, os fatores causais mais importantes. Um cenário mais plausível parece ser uma interação complexa entre ambos, do ponto de vista teórico, onde o estresse econômico desencadeia o crime "dependendo" do estado de integração social em seus vários níveis (família, trabalho, comunidade, inserção política, etc.), bem como de seus mecanismos protetores contra o crime (como a repressão). A começar pelos fatores "essencialmente sociais", temos: 
a) A porcentagem de apenados que eram trabalhadores rurais diminuiu de $15 \%$ para $11 \%$, seguindo a tendência de organização do estado e apontando para um crescimento hipotético nos crimes relacionados à propriedade, sugerindo que, nas áreas rurais, a criminalidade tende a estar mais relacionada às pessoas do que à propriedade. A partir daqui, também se podem esperar aumentos na reincidência a partir de uma associação aceita deste com os crimes relacionados à propriedade.

b) A escolaridade da população carcerária aumentou no período, como segue:

- as proporções de analfabetos e dos que têm educação fundamental incompleta diminuiu de $16 \%$ para $13,6 \%$.

- ao mesmo tempo, a proporção dos que têm educação fundamental completa subiu de $11,5 \%$ para 17,5\%, e dos que têm educação secundária - incompleta ou completa - passou de 4,99\% para 11,1\%, e de $2,38 \%$ para $7,33 \%$, respectivamente.

Essas transformações podem muito bem estar relacionadas à reincidência. Entretanto, em termos teóricos, não há forma de especificarmos em qual direção.

c) As relações extraprisionais, indicadas pelo recebimento de correspondência e de visitas, diminuíram durante o período (5\% e 30\%, respectivamente). Essas mudanças podem estar relacionadas ao enfraquecimento geral dos grupos sociais primários na sociedade moderna em geral, que vem junto com a urbanização demográfica e cultural do país. Nesse caso, se há algo que se pode apontar, é a hipótese de uma associação causal com a reincidência, já que o enfraquecimento dos grupos primários deixa os apenados mais à mercê de seu novo contexto: o próprio meio social prisional.

d) A proporção de apenados que têm documentos oficiais (carteiras de motorista, carteiras de trabalho, certidões de nascimento e certificados de reservista) permaneceu bastante semelhante, com exceção da cartei- 
ra de identidade nacional, a qual aumentou de $25 \%$ para $34 \%$ durante o período. Teoricamente, tal mudança está de acordo com o aumento nos crimes contra a propriedade em relação aos crimes contra a pessoa, no momento em que a sociedade avança para a concretização do processo de urbanização demográfica e cultural citado anteriormente.

Resumindo os quatro pontos acima, podemos levantar a hipótese de que a população carcerária mais urbanizada e desprovida de vínculos sociais gerou um aumento no volume geral de criminalidade, especificamente em termos de crimes contra a propriedade, de certa forma contrabalançada, talvez, pelos níveis crescentes de educação. Esta tendência, por sua vez, leva a um aumento esperado na reincidência, já que este fenômeno parece ocorrer com mais probabilidade entre aqueles que cometem crimes contra propriedade do que nos envolvidos em crimes contra a pessoa. Obviamente, é impossível obtermos avaliações específicas com relação às quantidades envolvidas nessas influências causais, a partir desta análise global da mudança ao longo do tempo.

Voltemos agora nossas atenções à esfera de influências econômicas. Podemos identificar as seguintes tendências principais:

e) A proporção de apenados que contribuem para a previdência social diminuiu de $19 \%$ para $11 \%$, e a quantidade daqueles cuja família possui "recursos próprios"_(qualquer tipo de bens de capital) diminuiu de 12\% para 8\%. Esta é uma primeira indicação da possibilidade de que o aumento geral no volume de crimes no período esteja relacionado também à deterioração das condições econômicas da população geral. Podemos levantar a hipótese de que a reincidência criminal, por sua vez, esteja ligada positivamente aos crimes relacionados às pressões econômicas, em função da associação teoricamente sustentável entre estes e os crimes contra a propriedade - os quais constituem, como indicado anteriormente, a tendência contemporânea.

f) A proporção de apenados com antecedentes de prisão na condição de menores apresentou uma leve diminuição proporcional (de 5,1\% para 
$3,16 \%$ ). Este resultado pode não estar relacionado a uma diminuição simplista no início das carreiras criminais na adolescência, mas sim ao aumento da proporção da atividade criminal desencadeada pelas condições econômicas, que atinge com mais gravidade a população em estágios posteriores da vida (adultos), principalmente as responsabilidades familiares de natureza econômica. Pode-se esperar que a reincidência cresça pela mesma razão da questão anterior, estabelecendo uma relação com as pressões econômicas, através do crime contra a propriedade.

g) A composição da população carcerária em termos de estado civil foi alterada de duas maneiras principais: a proporção de solteiros diminuiu de $69,4 \%$ para $64 \%$, ao passo que a proporção de uniões informais aumentou de $2,65 \%$ para $6,99 \%$. Podemos relacionar essas mudanças hipoteticamente, mais uma vez, a um aumento no crime derivado das questões econômicas, supondo-se que a criminalidade entre solteiros esteja mais relacionada à falta de proteção psicológica oferecida pela unidade familiar, do que o crime entre casados, mais ligado à pressão econômica. Mais uma vez, se estabelece uma associação com a reincidência.

h) A proporção de apenados sem descendentes diminuiu de $54,8 \%$ para 48,3\%; ainda assim, as proporções daqueles que têm 1, 2 e 3 descendentes se elevaram de $18,2 \%$ para $20,7 \%$, de $18,6 \%$ para $14,2 \%$, e de $5,81 \%$ para $7,48 \%$. Novamente, em sintonia com o argumento anterior, se podem sugerir esses números como um indicativo de que cada vez mais se cometem crimes por questões de sobrevivência familiar (econômica), bem como estabelecer uma relação com a reincidência.

i) O perfil etário da população carcerária mudou de forma significativa: a média de idade permaneceu estável até cerca de 1990, em torno de 30 anos. No entanto, a partir dali, ela tem aumentado de 30,1 em 1991, para 33,9 em 1997. Assim, considerando que o crime é - ceteris paribus - associado negativamente à idade no âmbito da população economicamente ativa, o envelhecimento da população carcerária pode ser visto como resultado do aumento 
da instabilidade ocupacional - e, portanto, psicológica - no país.

Resumindo-se os cinco últimos pontos, podemos apresentar a hipótese de que a deterioração das condições econômicas, em termos gerais, bem como para os grupos etários e de estado civil específicos, tende a elevar o crime contra a propriedade e, através dele, gerar um aumento na reincidência. A seguir, desenvolvemos a análise multivariada dos dados prisionais.

\section{Análise da regressão step-wise}

A Tabela 2 apresenta o conjunto original de variáveis independentes, a partir do qual o procedimento step-wise selecionou aqueles cuja associação com a reincidência é mais elevada e significativa.

a) Em primeiro lugar, observamos um modelo de ajuste muito bem sucedido, explicando 57\% da variância explicados. Obviamente, isso não significa que todos mecanismos subjacentes que estabelecem a relação desses indicadores com a reincidência estejam bem explicados, ou mesmo, explicados superficialmente. Também não se deve perder de vista o fato de que a alocação de apenados a determinados presídios não é totalmente aleatória e, assim sendo, parte da variância corresponde a políticas implementadas, as quais não são planejadas com rigor e mudam com freqüência. Estas fontes de variação não estão incluídas em nosso modelo, o qual está relacionado apenas a fatores sociofactuais, o que só faz fortalecer o ajuste.

b) Dezesseis por cento da variação (de 45\% para 57\%) são explicados pelas condições prisionais, depois de forçarmos todos os indicadores de situação biográfica e jurídica na equação (nessa ordem, teoricamente necessária). Os antecedentes socioeconômicos dos apenados explicam 32\% da variação, ao passo que $17 \%$ são explicados pela situação jurídica dos apenados. Isso significa que, a partir da experiência prisional recente no estado, existe espaço razoável para o estabelecimento de políticas com relação às condições dos presídios, com boas possibilidades de sucesso. 
Tabela 2. Indicadores selecionados de características biográficas, jurídicas e prisionais dos presídios

\begin{tabular}{|c|c|c|c|c|c|}
\hline \multirow{4}{*}{ Cor } & Negros & \multirow{4}{*}{ Pessoal } & $\begin{array}{l}\text { Funcionário de } \\
\text { Segurança/ preso }\end{array}$ & \multirow{4}{*}{ Filhos } & Sem \\
\hline & Brancos & & $\begin{array}{c}\text { Total } \\
\text { tuncionários/ } \\
\text { preso }\end{array}$ & & 1 \\
\hline & Mulatos & & $\begin{array}{l}\text { Média de } \\
\text { Instrução dos } \\
\text { Funcionários }\end{array}$ & & 2 \\
\hline & Pardos & & $\begin{array}{c}\text { Funcion. protiss./ } \\
\text { total }\end{array}$ & & 3 ou mais \\
\hline \multirow{5}{*}{ Religião } & Católicos & \multirow{5}{*}{ Trabalho } & $\begin{array}{l}\text { Proporção com } \\
\text { trabalho pago }\end{array}$ & \multirow{7}{*}{ Instrução } & Analfabeto \\
\hline & Protestantes & & $\begin{array}{c}\text { Proporção com } \\
\text { trabalho não } \\
\text { pago }\end{array}$ & & $\begin{array}{l}\text { Primário } \\
\text { incompleto }\end{array}$ \\
\hline & Espíritas & & $\begin{array}{l}\text { Presídio com } \\
\text { trabalho Interno }\end{array}$ & & $\begin{array}{l}\text { Primário } \\
\text { completo }\end{array}$ \\
\hline & Umbandistas & & $\begin{array}{l}\text { Proporção com } \\
\text { trabalho Externo }\end{array}$ & & $\begin{array}{l}\text { Secundário } \\
\text { incompleto }\end{array}$ \\
\hline & Outras & & $\begin{array}{l}\text { Proporção com } \\
\text { trabalho agrícola }\end{array}$ & & $\begin{array}{c}\text { Secundário } \\
\text { completo }\end{array}$ \\
\hline \multirow{5}{*}{ Estado civil } & Casados & \multirow{2}{*}{ Treinamento } & $\begin{array}{c}\text { Cursos } \\
\text { Profissionalizantes }\end{array}$ & & $\begin{array}{c}\text { Terceiro } \\
\text { grau } \\
\text { incompleto }\end{array}$ \\
\hline & Solteiros & & $\begin{array}{c}\text { Cursos em } \\
\text { educação geral }\end{array}$ & & $\begin{array}{l}\text { Terceiro } \\
\text { grau } \\
\text { completo }\end{array}$ \\
\hline & Divorciados & \multirow{3}{*}{ Instalações } & Presos/ vaga & & RS \\
\hline & Viúvos & & Q rea / vaga & & $\begin{array}{l}\text { Outros } \\
\text { Estados }\end{array}$ \\
\hline & Outros & & $\begin{array}{c}\text { Q rea Construída/ } \\
\text { preso }\end{array}$ & & $\begin{array}{l}\text { Outros } \\
\text { países }\end{array}$ \\
\hline \multirow{2}{*}{ Idade } & \multirow{2}{*}{ Média } & \multirow{2}{*}{$\begin{array}{l}\text { Assistência } \\
\text { Social }\end{array}$} & $\begin{array}{l}\text { Organizações } \\
\text { Assistenciais }\end{array}$ & & \\
\hline & & & $\begin{array}{c}\text { Conselhos } \\
\text { Prisionais }\end{array}$ & & \\
\hline
\end{tabular}

Fonte: Censo prisional e dados oficiais da SUSEPE (Superintendência de Serviços Penitenciários) do RS, para o período 1989-97. 
c) Dos dez indicadores incluídos na equação a partir das três dimensões, apenas quatro diminuem a reincidência: "proporção de não-brancos e não-negros"; "presídio com assistência de organizações privadas"; "proporção de apenados trabalhando na área rural"; e "presídios que oferecem trabalho interno". Estes indicadores respondem por 19\% da variância (próximo a um terço do ajuste). Isto dá uma idéia da presença um tanto fraca de efeitos compensatórios sobre a reincidência presentes nas tendências globais do estado, quando se compara com os dois terços remanescentes do ajuste explicados por fatores positivos.

Estes e outros resultados relacionados aos indicadores específicos escolhidos pelo procedimento step-wise são discutidos em detalhe a seguir.

a) Com relação aos antecedentes socioeconômicos, a primeira variável a ser inserida foi a dos umbandistas, com um ganho em $\mathrm{R}^{2}$ de 0,10 (o maior na equação). Teoricamente, é claro que não é a natureza da preferência religiosa, em si, que é associada à reincidência; ao invés disso, é provável que seja a situação socioeconômica associada à Umbanda a responsável por essa vinculação empírica. Ainda assim, dentro do fator de pressão econômica, encontramos a segunda variável inserida na equação, o trabalho não-qualificado, com um ganho em $R^{2}$ de 0,06 . Seu conteúdo não deixa dúvidas com relação ao caráter de pressão econômica subjacente a seu impacto sobre a reincidência. Por fim, a pressão econômica está, muito provavelmente, por detrás da quinta variável inserida na equação, que foi a "proporção de apenados com três descendentes ou mais", que apresenta um ganho de $\mathrm{R}^{2}$ de 0,06 .

Estes indicadores de pressão econômica, juntos, explicam 22\% da variância (exatamente um terço da variância total explicada). Os resultados são coerentes com a nossa análise de mudança global ao longo do tempo, onde parte da reincidência foi hipoteticamente relacionada à pressão econômica.

Ainda no âmbito dos antecedentes socioeconômicos, encontramos dois resultados complexos (terceira e quarta variáveis inseridas na equação): o impacto positivo do catolicismo e o impacto negativo de "não- 
brancos" e "não-negros". Esses resultados são aqui considerados apenas como indicações empíricas para a investigação, que demandam muito mais base de pesquisa para permitir qualquer tipo de interpretação.

b) Com relação ao status jurídico dos apenados, apenas uma variável, o roubo, surgiu com um efeito importante sobre a reincidência. Sua contribuição para o ajuste do modelo é, contudo, a segunda maior $(0,09)$. Fica claro que, a partir de uma perspectiva teórica, o relacionamento entre roubo e reincidência passa, em grande parte, pela pressão econômica.

c) Os indicadores relacionados às condições prisionais abarcam três fatores ligados a oportunidades de trabalho para os apenados. No entanto, enquanto dois deles - "proporção dos que trabalham na agricultura" (ou seja, trabalham em colônias agrícolas) com um ganho em $\mathrm{R}^{2}$ de $4 \%$, "presídios que oferecem trabalho interno", com um ganho de $3 \%$ em R ${ }^{2}$ - têm uma relação negativa com a reincidência, outro, "trabalhos pagos", está positivamente relacionado a esse fator. Dessa forma, a direção dos efeitos do trabalho depende da existência ou não de remuneração. Nesse caso, é possível argumentar teoricamente que não é o pagamento em si que causa reincidência; em vez disso, a escolha dos apenados para executar os trabalhos pagos ou algum outro fator nãoespontâneo está revertendo o efeito "natural" do trabalho pago. Nesse caso, também é necessário realizar mais pesquisa.

Com relação a essa associação geral entre reincidência e trabalho, devemos ter em mente, a partir da análise global do período, que, de 1989 a 1997, houve uma diminuição tanto nos presídios que ofereciam qualquer tipo de trabalho para os apenados quanto no número de apenados que trabalhavam. Esta tendência descendente poderia ser revertida na direção de escolhas aqui mencionada, com grandes possibilidades de sucesso em diminuir a reincidência.

Por fim, a presença de organizações privadas que ofereciam assistência social aos apenados ("Organizações privadas prestando assistência no 
presídio") surgiu como um fator importante relacionado negativamente à reincidência. Também nesse caso, a análise da mudança ao longo do tempo revelou uma queda significativa, que também poderia ser tratada com grandes possibilidades de sucesso.

Tabela 3. Regressão Step-wise Relacionando Reincidência Criminal com Antecedentes Socioeconômicos, Status Jurídico e Condições Prisionais: RS, Brasil, 1989-1997

\begin{tabular}{|c|c|c|c|c|c|c|c|c|}
\hline Variável & B & $\begin{array}{c}\text { Erro } \\
\text { Padrão }\end{array}$ & $\beta$. & $\begin{array}{l}\text { Nível de } \\
\text { Sig. }\end{array}$ & $\mathbf{R}^{2}$ & $\begin{array}{l}\text { Ganho } \\
\mathrm{emR}^{2}\end{array}$ & Passo & Bloco \\
\hline $\begin{array}{l}\text { Proporção de } \\
\text { umbandistas }\end{array}$ & .10 & .02 & .42 & .00 & .10 & .10 & 1 & 1 \\
\hline $\begin{array}{l}\text { Proporção sem } \\
\text { Qualificação } \\
\text { profissional }\end{array}$ & .04 & .02 & .13 & .06 & .06 & .16 & 2 & 1 \\
\hline $\begin{array}{l}\text { Proporção de } \\
\text { católicos }\end{array}$ & .01 & .00 & .19 & .02 & .05 & .21 & 3 & 1 \\
\hline $\begin{array}{c}\text { Proporção de não- } \\
\text { brancos e não-negros }\end{array}$ & -.03 & .01 & -.17 & .02 & .05 & .26 & 4 & 1 \\
\hline $\begin{array}{l}\text { Proporção com } 3 \text { ou } \\
\text { mais descendentes }\end{array}$ & .05 & .02 & .19 & .00 & .06 & .32 & 5 & 1 \\
\hline $\begin{array}{c}\text { Proporção dos que } \\
\text { cometeram crime de } \\
\text { roubo }\end{array}$ & .06 & .01 & .31 & .00 & .09 & .41 & 6 & 2 \\
\hline $\begin{array}{c}\text { Organizações } \\
\text { privadas prestando } \\
\text { assistência ao } \\
\text { presídio }\end{array}$ & -.03 & .01 & -.22 & .00 & .05 & .46 & 7 & 3 \\
\hline $\begin{array}{c}\text { Proporção com } \\
\text { trabalho remunerado }\end{array}$ & .01 & .00 & .32 & .00 & .04 & .50 & 8 & 3 \\
\hline $\begin{array}{c}\text { Proporção que } \\
\text { trabalha na agricultura }\end{array}$ & -.03 & .01 & -.21 & .01 & .04 & .54 & 9 & 3 \\
\hline $\begin{array}{c}\text { Presídio que oferece } \\
\text { trabalho interno }\end{array}$ & -.03 & .01 & -.15 & .03 & .05 & .57 & 10 & 3 \\
\hline
\end{tabular}




\section{Conclusões}

As análises estatísticas apresentadas na seção anterior falam por si próprias, de forma contundente e concisa, dispensando a recapitulação necessária em outros casos. Há porém algumas considerações mais gerais no tocante à natureza do fator socioeconômico, assim como a questão da filosofia prisional, que merecem explicitação.

Quanto ao fator socioeconômico, é importante alertar para o fato de que não é a pobreza, per se, que está necessariamente por trás do fator em questão. Isto porque a relação positiva geral detectada entre o status econômico e reincidência não contempla a questão das interatividades e curvilinearidades; a partir destas últimas poderá futuramente constatar-se que nos níveis mais agudos de pobreza a criminalidade nem é tão freqüente, nem se manifesta nas suas formas mais graves. O impacto do status econômico poderá estar mais associado com quedas nas condições de vida e com a chamada "anomia econômica", isto é, a incapacidade de atingir os níveis de vida culturalmente estabelecidos e esperados em função da inexistência dos meios necessários.

Quanto à filosofia prisional, lembremos que a idéia de re-socialização ou reabilitação do apenado passa hoje por uma fase de enorme desprestigio nas esferas tanto nacional como internacional, especialmente nos Estados Unidos. As enormes massas de encarcerados, o alcance até agora bastante limitado dos programas de reabilitação, e os altos custos envolvidos em novos ou aperfeiçoados programas para os grandes contingentes atuais de apenados, tem levado a política carcerária nesse país a optar pela chamada new penology. Esta nova filosofia envolve o abandono da individualização do tratamento e da idéia de re-socialização, em favor do "gerenciamento" das populações carcerárias em função da avaliação dos diferentes graus de risco que diferentes grupos de delinqüentes oferecem à sociedade. Várias formas de regimes abertos e semi-abertos, liberdade condicional e outras "penas alternativas" tem ocupado todos os espaços da prática e discussão sobre filosofia prisional, inclusive no Brasil. 
Ora, independentemente do mérito inquestionável desta nova tendência, o problema da reincidência e da re-socialização continua em aberto, mais ainda em função dos indícios claros de que a reincidência acontece em forma desproporcional entre os grupos que gozam de, e enquanto gozam de, liberdades parciais. Não obstante as considerações feitas acima sobre a natureza dos condicionantes econômicos da reincidência, é claro que na sociedade do bem-estar social, a problemática econômica relacionada ao crime é mito mais "social" (relativa à anomia), enquanto no terceiro mundo esta é muito mais "econômica" (relativa a necessidades básicas). Assim sendo, a viabilização de oportunidades é um caminho muito mais natural e urgente no meio Brasileiro.

Finalmente cabe indicar que o caminho da ilegalidade no Brasil, especialmente entre os jovens, dá mostras de ser um fenômeno de "status" entre muitos grupos socialmente excluídos ou marginalizados, e que as prisões se constituem cada vez mais em canalizadores do processo: a experiência prisional de um jovem, possivelmente um "líder" ou "anti-herói", resulta facilmente na organização de uma gangue criminal. Nesse tipo de cenário, a qualificação da experiência prisional, alternativa ou não, parece decisiva na preservação e reconquista da cidadania e portanto, da paz social.

\section{Referências}

ALEXANDER, C. From Dreamtime to Nightmare. The Voices of 168 Aboriginal ExPrisoners in New South Wales. Australian and New Zealand, Journal of Sociology, 23, 3, Nov., 1987, p. 323-342.

ALEXANDER Jr., Rudolph e NICKERSON, Nancy. Predictors and Non-predictors of Recidivism in Female Offenders. Free Inquiry in: Creative Sociology, 21, 2, Nov., 1993, p. 141-148.

BLOCK, Caroline e VAN-DER-WERFF, C. Career criminals in the Netherlands: who are the most active and most dangerous offenders? ASA Association paper, 1987. 
BLUMSTEIN, Alfred e GRADDY, E. Prevalence and recidivism in index arrests: a feedback model. Law and Society Review, 82, 16, 2, Apr., 1981, p. 265-290.

BROADHURST, R. e LOH, N. S. Rearrest probabilities for the 1984-1993 apprehended western Australian population: a survival analysis. Journal of Quantitative Criminology, 111, 3 Set., 1995, p. 289-313.

DESROCHES, Frederick. Post-Secondary education in prison: the Canadian experience. International Sociological association/ Sociology of Education Section. Association paper, 1984.

DOS SANTOS, José Vicente T. et al. A violência no RS. Relatório de Pesquisa Aplicada. Convênio UFRGS - Secretaria de Justiça do RS. N.P., Janeiro, 1997.

ECKERED, Jack. Responsibility, Love and Privatization: A Businessman Guide to Criminal Rehabilitation. Policy Review, 45, Verão, 1988, p. 52-55.

ENOCKSSON, Karin. Correctional programs: a review of the value of education and training in penal institutions. Journal of Offender Counseling Services and Rehabilitation, 5, 1, Outono, 1980, p. 5-18.

HASSIN, Yael. Clinical versus statistical prediction: the case of the individual pardon board and the early release committees for prisoners. Crime and Social Deviance, 12, 1984, p. 65-85.

HASSIN, Yael. Two models for predicting recidivism: clinical vs. statistical - another view. British Journal of Criminology, 26, 3, Julho, 1986, p. 270-286.

Holland, Terril; LEVI, Mario. Personality correlates of extent vs. type of antisocial behavior among adult offenders: a multivariate analysis. Multivariate Behavioral Research, 18, 4, Out., 1983, p. 391-400.

LATTIMORE, Pamela; VISHER, Christy e LINSTER, Richard. Predicting Rearrest for Violence Among serious youthful Offenders. Journal of Research in: Crime and Delinquency, 32, 1, Fev., 1995, p. 54-83.

LENKE, Leif; VON HOFFER, Hans; THORSONN, UIf e LEANDER, Karen. Problems Associated with the Production of Statistics on Recidivism. Statistisk Tidkrift, 3, 1982, p. 208-214. 
MARTINEZ, Ramiro. Violent Crimes and Patters of Rearrest. American Sociological Association (Paper), 1992.

McCORD, William e SANCHEZ, J. The treatment of deviant children. Crime and Delinquency, 29, 2, Apr., 1983, p. 238-253.

NAGIN, Daniel e FARRINGTON, D. The stability of criminal potential from childhood to adulthood. Criminology, 30, 2, Maio, 1992, p. 235-260.

RIENERTH, Janice G. Recidivism: what is It? Society for the study of social problems (Association Paper), 1991.

SALEM, Richard G. Crime, Public Policy and Woman Battering. Sociological Imagination, 32, 3-4, 1995, p. 197-204.

SHABBACH, Leticia et al. Sistema Penitenciário do Rio Grande do Sul: evolução histórica e análise da reincidência. Secretaria da Justiça do RS. Np., s/d, 1997.

SHERMAN, Lawrence; SMITH, D.; SCHMIDT, J. e ROGAN, D. Crime, punishment and stake in conformity: legal and informal control of domestic Violence. American Sociological Review, 57, 5, Out., 1992, p. 680-690.

SHOVER, Neal e HONAKER, David. The socially bounded decision making of persistent property offenders. Howard Journal of Criminal Justice, 31, 4, Nov., 1992, p. 276-293.

SIGLER, Robert. Criminal justice evaluation research and theory research. Free Inquiry in Creative Sociology, 12, 1, Maio, 1984, p. 9-12.

SMITH, William R. The effects of base rate and cutoff point choice on commonly used measures of association and accuracy on recidivism research. Journal of Quantitative Criminology, 12, 1, Março, 1996, p. 83-111.

WEISBURD, David; WARING, E.; CHAYET, E. Specific deterrence in a sample of offenders convicted of white collar crime. Criminology, 33, 4, Nov., 1995, p. 587 607 . 
Sociologias, Porto Alegre, ano 4, no 8, jul/dez 2002, p. 220-244

\section{Resumo}

O objetivo central do trabalho é identificar e mensurar o poder explicativo relativo das seguintes três dimensões causais hipotéticas da reincidência criminal: a) variáveis biográficas ou socioeconômicas, a saber: estado civil, filhos, naturalidade, idade, religião, raça, instrução formal e nível de qualificação da ocupação; b) tipo de delito, segundo os seguintes oito tipos simplificados: homicídios, lesões corporais, roubos, furtos, estelionatos, posse e uso de entorpecentes e estupros); e c) condições de prisão, incluindo a disponibilidade e qualificação dos funcionários - tanto de segurança quanto administrativos -, trabalho prisional dos apenados, treinamento profissionalizante e instrução em geral, espaços disponíveis e superlotação, e programas de assistência social ao apenado. O trabalho resume e avalia a literatura internacional relativa à reincidência criminal, tanto em termos metodológicos quanto teóricos, e apresenta um panorama histórico recente da criminalidade no estado do Rio Grande do Sul, como pano de fundo da análise da reincidência propriamente dita. Utilizando dados longitudinais oficiais das prisões para os anos de 1989 a 1997, e o cadastro geral oficial de apenados do estado, uma série de regressões é calculada pelo método step-wise, relacionando as três dimensões em questão com a variável reincidência, dicotomizada. A dimensão biográfica explica $32 \%$ da reincidência, o tipo de crime explica outros $9 \%$, e as condições de prisão explicam ainda $16 \%$, sugerindo uma ampla influência da política prisional na redução da reincidência.

Palavras-chave: reincidência criminal, base socioeconômica, delito, condições de prisão, programas de assistência prisional. 